\title{
The catalytic oxidation of toluene at low temperature over palladium nanoparticles supported on Alumina sphere catalysts: effects of Palladium precursors and preparation method
}

\author{
Thien Huu Pham ${ }^{1}$, Ha An Quoc Than', Ha Manh Bui ${ }^{2,3^{*}}$ \\ ${ }^{1}$ Institute of Applied Materials Science - VAST, No 1A TL 29 St., Thanh Loc Ward, District 12, Ho Chi Minh city \\ 700000, Vietnam \\ ${ }^{2}$ Department of Environmental Sciences, Saigon University, 273 An Duong Vuong St., District 5, Ho Chi Minh city \\ 700000, Vietnam \\ ${ }^{3}$ NTT Institute of High Technology, Nguyen Tat Thanh University, 300A Nguyen Tat Thanh Street, District 4, Ho Chi \\ Minh City 700000, Vietnam \\ "Corresponding author: e-mail: manhhakg@yahoo.com.vn
}

\begin{abstract}
In this study, 1 wt.\% $\mathrm{Pd} / \mathrm{Al}_{2} \mathrm{O}_{3}$ sphere catalysts were prepared using the wet-impregnation (WI) and depositionprecipitation (DP) method using palladium chloride and tetraamminepalladium (II) nitrate as salt precursors. All catalysts were characterized using X-ray diffraction (XRD), transmission electron microscopy (TEM) and Fouriertransform infrared (FTIR) spectroscopy. The catalytic activity in toluene oxidation under gas-phase conditions was measured. The obtained results showed that metal dispersion and catalytic activity were strongly dependent on the salt precursor and method of catalyst preparation. The use of tetraamminepalladium (II) nitrate as the precursor presented smaller particle size, an enhanced dispersion and higher specific surface area. Moreover, the catalyst prepared with this precursor also showed higher catalytic activity than that prepared with palladium chloride. At $1 \mathrm{wt} . \%$ Pd loading, complete oxidation of toluene was achieved at $250^{\circ} \mathrm{C}$. However, there was only approximately 80-90\% efficient at the same temperature when the catalyst was prepared with palladium chloride as the precursor.
\end{abstract}

Keywords: $\mathrm{Pd} / \mathrm{Al}_{2} \mathrm{O}_{3}$ spheres, wet-impregnation, deposition-precipitation, catalytic oxidation.

\section{INTRODUCTION}

Benzene, toluene and xylene compounds (BTX) are known to be a major contributor to air pollution and have a high toxic potential toward human beings ${ }^{1}$. In some reviews, the main sources of BTX have been determined as the waste gases of chemical, petrochemical and related industries ${ }^{2}$. Among the many technologies available for removing BTX, the catalytic oxidation technology has been identified as the most efficient way. In this technology, catalysts play an importance role due to they have higher destructive efficiency. In this way, supported noble metals $(\mathrm{Pt}, \mathrm{Pd}, \mathrm{Rh}$, and $\mathrm{Ag}$ ) are considered promising catalysts for oxidation of BTX in low temperatures ${ }^{3,4}$. Among them, Pd based catalysts have been indicated in the literature as the best choice in BTX combustion at low temperature ${ }^{5}$.

In recent studies, Panpranot, et al. (2005) ${ }^{6}$ and Abedini, et al. $(2012)^{7}$ have reported that the principal factors currently used to treat BTX with catalytic oxidation are the following: composition of palladium phase, particle size and the dispersion on different support. Furthermore, activity and morphology of Pd-based catalysts are affected by Pd precursors and the preparation method of the catalyst ${ }^{6,8}$.

In this study, the effects of the preparation method and different salt precursors were examined for $1 \mathrm{wt} . \%$ $\mathrm{Pd} / \mathrm{Al}_{2} \mathrm{O}_{3}$ sphere catalysts. The catalytic activity was tested for complete oxidation of toluene in the gas phase.

\section{MATERIAL AND METHODS}

\section{Materials and measurements}

The 1 wt. $\% \mathrm{Pd} / \mathrm{Al}_{2} \mathrm{O}_{3}$ sphere catalysts were prepared using different routes and different precursors. One of the routes, the wetness-impregnation (WI) technique with $\mathrm{Al}_{2} \mathrm{O}_{3}$ spheres (SASOL, $1.0 \mathrm{~mm} ; 170 \mathrm{~m}^{2} \mathrm{~g}^{-1}$ ) and aqueous solution containing the appropriate amount of $\mathrm{Pd}(\mathrm{N}-$ $\left.\mathrm{H}_{4}\right)_{3}\left(\mathrm{NO}_{3}\right)_{2}$ (catalysts denoted as $1 \%$ WI-A) and $\mathrm{PdCl}_{2}$ (catalysts denoted as $1 \% \mathrm{WI}-\mathrm{Cl}$ ), supplied by Merck, respectively. In the other route, the deposition-precipitation (DP) technique of $\mathrm{PdCl}_{2}$ (catalysts denoted as $1 \%$ DP-Cl) with $\mathrm{NaOH}$ was used as a precipitating agent. The $\mathrm{pH}$ of the solution was $8-10$. For both methods, the excess water was removed in a rotary evaporator at $80^{\circ} \mathrm{C}$, and the product was isolated by suction filtration after stirring for three hours. The samples were dried and calcined at $550^{\circ} \mathrm{C}$ for four hours in air to decompose the metal salt supported on the $\mathrm{Al}_{2} \mathrm{O}_{3}$ sphere support.

Catalyst characterization

The X-ray diffraction (XRD) patterns of the catalyst samples were analysed using a Bruker D5005. The instrument was equipped with a $\mathrm{Cu}-\mathrm{K} \alpha$ radiation source conducted in the $2 \theta$ range from $30-80$, with a scanning rate of $3 \mathrm{~min}^{-1}$ and a step size of 0.03 . Transmission electron microscopy (TEM) images were obtained with a TACHI H-7500 (Japan) divide with $200 \mathrm{KV}$ acceleration voltage. Fourier-transform infrared (FTIR) spectroscopy was calculated at spectral resolution of $4 \mathrm{~cm}^{-1}$ between 400 and $4000 \mathrm{~cm}^{-1}$ using a Perkin-Elmer 1600 series spectrometer. 


\section{Activity test of catalysts}

Toluene oxidation was performed in a continuous flow-fixed bed reactor with temperatures in the range of $30-300^{\circ} \mathrm{C}$. The total flow through the catalyst bed was kept at $1 \mathrm{~L} \mathrm{~min}^{-1}$ leading a weight hourly space velocity (GHSV) of about 15,000 $\mathrm{h}^{-1}$. The initial toluene concentration was fixed at about $1000 \mathrm{ppm}$. The reactant and reaction products were analysed in situ using a Clarus 680 gas chromatograph (GC) with an HP-5MS capillary column.

\section{RESULTS AND DISCUSSION}

\section{Effect of catalyst characterization}

The XRD patterns of the three catalysts are shown in Figure 1. The alumina phase was presented with the characteristic peaks of $\gamma$-alumina phase at $37.2^{\circ}, 45.6^{\circ}$, $62.3^{\circ}$ and $66.9^{\circ}$ in agreement with the Joint Committee of Powder Standard Diffraction Standards (JCPDS-ICDD Card № 00-010-0425).

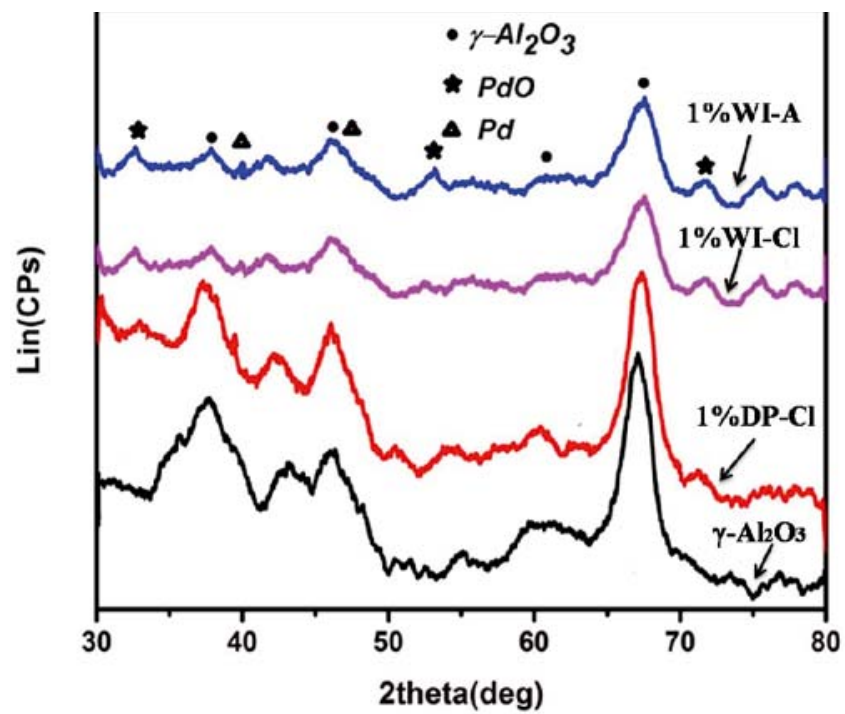

Figure 1. XRD patterns of the catalysts $\gamma-\mathrm{Al}_{2} \mathrm{O}_{3}, 1 \% \mathrm{DP}-\mathrm{Cl}$, $1 \%$ WI-Cl and $1 \%$ WI-A

Besides $\gamma$-alumina, in the impregnated samples (1\%WI-Cl, $1 \%$ WI-A), the PdO phase was identified by XRD reflections at $2 \theta=32.9,54$ and 72.3 (PDF 41-1107). In addition, the diffraction lines at $2 \theta=40.2,46.6(\mathrm{PDF}$ 87-0639) are characteristic of the metallic $\mathrm{Pd}$ phase. Figure 1 also shows $\mathrm{PdO}$ phase in the 1\% DP-Cl sample with weak signal. However, the metallic Pd phase was appeared clearly.

Complementary data involving the dispersion of $\mathrm{PdO}$ and Pd phase have been shown by TEM analysis of the $\mathrm{Pd} / \mathrm{Al}_{2} \mathrm{O}_{3}$ spheres catalysts (Figure 2). The $\mathrm{Pd}$ and $\mathrm{PdO}$ particles had a spherical morphology and a crystalline particle diameter of around $4-5 \mathrm{~nm}$. Figure 2 also illustrated the active phase of palladium disperses well on the surface of the support on all catalysts. However, compared with two catalysts, $1 \%$ WI-A catalyst indicated a high dispersion of the active phase on the alumina support. Furthermore, the results obtained by TEM analysis, which were in line with the XRD results, showed that the use of tetraamminepalladium (II) nitrate was a precursor for the formation of well-dispersed $\mathrm{PdO}$
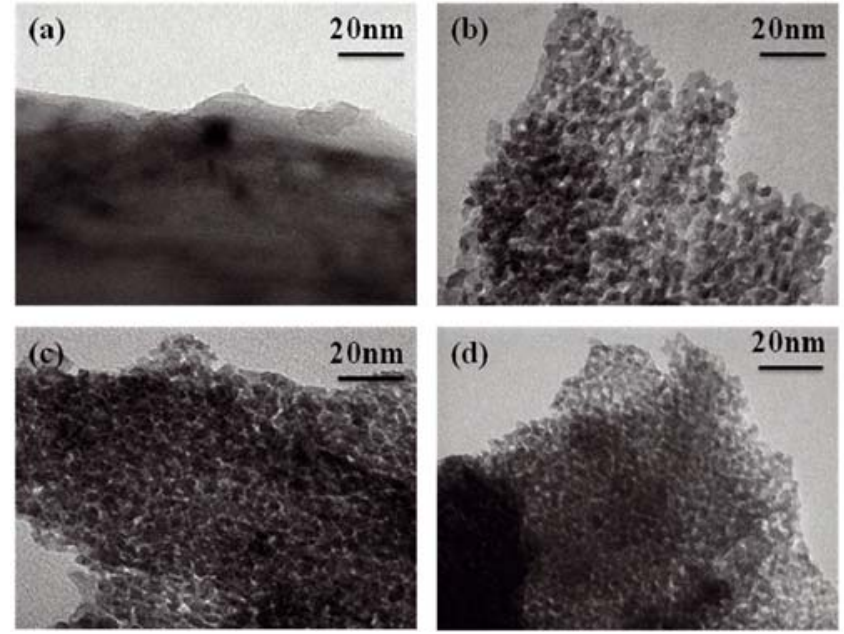

Figure 2. TEM images of the catalysts (a) $\gamma-\mathrm{Al}_{2} \mathrm{O}_{3}$, (b) $1 \%$ DP$-\mathrm{Cl}$, (c) $1 \% \mathrm{WI}-\mathrm{Cl}$, and (d) $1 \% \mathrm{WI}-\mathrm{A}(167,000 \mathrm{x})$

and $\mathrm{Pd}$ particles, in accordance with the results reported by Pham et al. ${ }^{\text {. }}$

To demonstrate the presence of the functional group in the $\mathrm{Pd} / \mathrm{Al}_{2} \mathrm{O}_{3}$ catalyst, the results of FTIR spectra are shown in Figure 3 . The band at $3365-3450 \mathrm{~cm}^{-1}$ and $1639 \mathrm{~cm}^{-1}$ belonged to the stretching vibration of the $\mathrm{O}-\mathrm{H}$ group absorbed on the surface or inside of the $\mathrm{Al}_{2} \mathrm{O}_{3}$ support structure ${ }^{\mathbf{1 0}, \mathbf{1 1}}$. The band at $610 \mathrm{~cm}^{-1}$ was attributed to the $\mathrm{Pd}-\mathrm{O}$ vibrations, which suggested that $\mathrm{Pd}$ was attached to $\mathrm{Al}_{2} \mathrm{O}_{3}$. At $719 \mathrm{~cm}^{-1}$, the $\mathrm{Al}-\mathrm{O}$ bond represented the support component. Similarly, the IR spectra of the $1 \%$ WI-A sample showed Pd-O-Pd bond at $792 \mathrm{~cm}^{-1}$ in addition to the characteristic peaks. This again confirmed the presence of palladium phases in the composition of the material that was synthesized. This result was completely consistent with the XRD spectra related above.

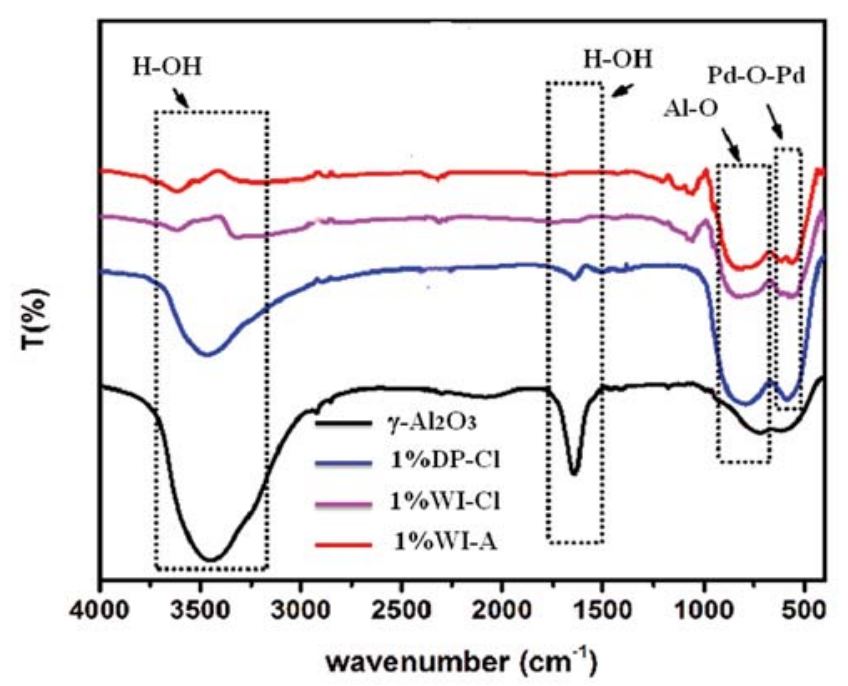

Figure 3. FTIR spectra of the catalysts $\gamma-\mathrm{Al}_{2} \mathrm{O}_{3}, 1 \% \mathrm{DP}-\mathrm{Cl}$, $1 \%$ WI-Cl and $1 \%$ WI-A

\section{Effect of preparation and palladium precursors}

The toluene oxidation results for various $1 \mathrm{wt} \% \mathrm{Pd} /$ $\mathrm{Al}_{2} \mathrm{O}_{3}$ sphere catalysts are shown in Figure 4. As can be seen in this figure, the oxidation reaction started at temperatures higher than $120^{\circ} \mathrm{C}$, over a catalyst with 


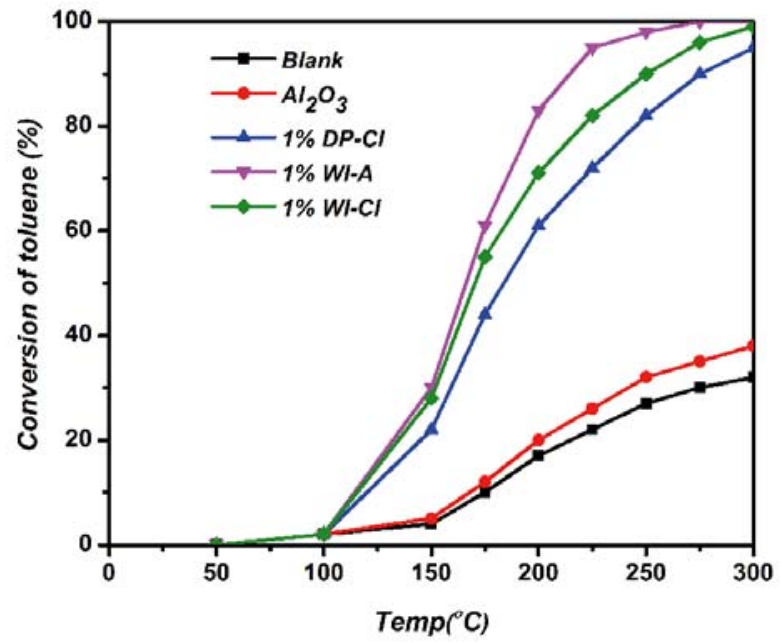

Figure 4. Toluene conversion curves of the catalysts $1 \% \mathrm{DP}-\mathrm{Cl}$, $1 \%$ WI-A and 1\% WI-Cl (toluene 1000 ppm, 20\% $\mathrm{O}_{2} / \mathrm{N}_{2}$, total flow rate $1 \mathrm{Lmin}^{-1}$, GHSV $15.000 \mathrm{~h}^{-1}$ )

an $\mathrm{Al}_{2} \mathrm{O}_{3}$ sphere support. However, only $32.1 \%$ of the toluene was converted at $250^{\circ} \mathrm{C}$.

Toluene combustion activity of the Pd-based catalysts was found to improve conversion efficiency. The $1 \%$ WI-A catalyst showed the best activity, and toluene conversion reached $98 \%$ at $250^{\circ} \mathrm{C}$. In contrast, the $1 \% \mathrm{DP}-\mathrm{Cl}$ catalyst was found to be less active compared to the other two catalysts; the total toluene conversion at $250^{\circ} \mathrm{C}$ reached about $80 \%$. The activity was as follows: $1 \%$ WI-A > $1 \%$ WI-Cl $>1 \%$ DP-Cl. Therefore, all results indicated that the tetraamminepalladium (II) nitrate precursor was more effective than the palladium chloride precursor. This was due to chloride residing on the catalyst surface even after calcinations at $600^{\circ} \mathrm{C}^{\mathbf{9}}$. These results were in agreement with the XRD data and TEM images. The data showed that there was a relation between the $\mathrm{PdO}$ and $\mathrm{Pd}$ particle sizes and the toluene oxidation of these catalysts. Highly effective catalysts produced the smallest palladium particles size and highest palladium dispersion ${ }^{\mathbf{4}, 10}$. These results indicated that using salt chloride directly was not effective for toluene oxidation.

\section{CONCLUSION}

In this study, the $1 \mathrm{wt} \% \mathrm{Pd} / \mathrm{Al}_{2} \mathrm{O}_{3}$ sphere catalysts were prepared using two different methods with two palladium precursors. The characteristic of obtained catalysts' $s$ from two methods such as composition, particle size and dispersion of palladium active phase on alumina spheres support demonstrated the great advantage of wetnessimpregnation as compared to deposition-precipitation method. The palladium catalysts obtained from the $1 \%$ WI-A also exhibited higher activity in toluene oxidation than the catalysts obtained from $1 \% \mathrm{WI}-\mathrm{Cl}$ and $1 \%$ DP-Cl. Furthermore, the higher dispersion and the smaller particle sizes of $\mathrm{PdO}$ and $\mathrm{Pd}$ resulted from the $1 \%$ WI-A catalyst with the highest catalytic activities. While the $1 \%$ DP-Cl catalyst exhibited lower activity than the $1 \% \mathrm{WI}-\mathrm{Cl}$. These conclusions are beneficial for catalytic performance enhancement.

\section{ACKNOWLEDGEMENTS}

This research founding from Vietnam National Foundation for Science and Technology Development (NAFOSTED) (Grant number: 103.99-2016.67) was acknowledged.

\section{LITERATURE CITED}

1. Ahmed, N., Ok, Y.S., Jeon, B.H., Kim, J.R., Chae, K.J. \& Oh, S.E. (2019). Assessment of benzene, toluene, ethyl-benzene, and xylene (BTEX) toxicity in soil using sulfur-oxidizing bacterial (SOB) bioassay. Chemosphere. 220, 651-657. DOI: 10.1016/j.chemosphere.2018.12.102.

2. Gallego, E., Roca, F.X., Guardino, X. \& Rosell, M.G. (2008). Indoor and outdoor BTX levels in Barcelona City metropolitan area and Catalan rural areas. J. Environ. Sci. 20, 1063-1069. DOI: 10.1016/S1001-0742(08)62150-6.

3. Torres, S.M., Marín, F.C., Cadenas, A.P. \& Hódar, F.J.M. (2015). Coupling Noble Metals and Carbon Supports in the Development of Combustion Catalysts for the Abatement of BTX Compounds in Air Streams. Catalysts. 5, 774-779. DOI: 10.3390/catal5020774.

4. Ihm, S.K., Jun, Y.D., Kim, D.C. \& Jeong, K.E. (2004). Low-temperature deactivation and oxidation state of $\mathrm{Pd} / \gamma-\mathrm{Al}_{2} \mathrm{O}_{3}$ catalysts for total oxidation of $\mathrm{n}$-hexane. Catalysis Today. 93, 149-154. DOI: 0.1016/j.cattod.2004.06.096.

5. Huang, S., Zhang, C. \& He, H. (2013). Effect of pretreatment on $\mathrm{Pd} / \mathrm{Al}_{2} \mathrm{O}_{3}$ catalyst for catalytic oxidation of o-xylene at low temperature. J. Environ. Sci. 25, 1206-1212. DOI: 10.1016/ S1001-0742(12)60169-7.

6. Panpranot, J., Tangjitwattakorn, O., Praserthdam, P. \& Goodwin Jr, J.G. (2005). Effects of Pd precursors on the catalytic activity and deactivation of silica-supported Pd catalysts in liquid phase hydrogenation. Appl. Catalysis A: General. 292, 322-327. DOI: 10.1016/j.apcata.2005.06.008.

7. Abedini, A., Saion, E., Larki, F., Zakaria, A., Noroozi, M. \& Soltani, N. (2012). Room temperature radiolytic synthesized $\mathrm{Cu} @ \mathrm{CuAlO}_{2}-\mathrm{Al}_{2} \mathrm{O}_{3}$ nanoparticles. Int. J. Molec. Sci. 13, 11941-11953. DOI: 10.3390/ijms130911941.

8. Pham, T.H., Bui, H.M. \& Khacef, A. (2018). Oxidation of propene from air by atmospheric plasma-catalytic hybrid system. J. Serbian Chem. Soc. 83, 641-649. DOI: 10.2298/ JSC171014012P.

9. Pham, T.H., Sivachandiran, L., Da Costa, P. \& Khacef, A. (2017). Methane, Propene and Toluene Oxidation by Plasma-Pd $/ \gamma-\mathrm{Al}_{2} \mathrm{O}_{3}$ Hybrid Reactor: Investigation of a Synergetic Effect. Topics in Catalysis. 60, 326-332. DOI: 10.1007/ s11244-016-0619-6.

10. Huang, S., Zhang, C. \& He, H. (2008). Complete oxidation of o-xylene over $\mathrm{Pd} / \mathrm{Al}_{2} \mathrm{O}_{3}$ catalyst at low temperature. Catalysis Today. 139, 15-23. DOI: 10.1016/j.cattod.2008.08.020.

11. Zhang, Z., Jiang, Z. \& Shangguan, W. (2016). Low-temperature catalysis for VOCs removal in technology and application: a state-of-the-art review. Catalysis Today. 264, 270-278. DOI: 10.1016/j.cattod.2015.10.040. 